\title{
EVOÉ, MEU REI! RAFAEL BASTOS ENTRE MUSAS E AMAZONAS
}

\author{
Guilherme Werlang* \\ University of St Andrews - Escócia
}

Vinte e um anos depois da sua primeira edição a republicação d' $A$ Musicológica Kamayurá: para uma antropologia da comunicação no Alto Xingu (1999) faz jus à saudação das mênades e bacantes a seu autor, Rafael José de Menezes Bastos, soteropolitano agora também ilhéu, ele mesmo encarnação de Másias ou Sileno, maraka ùp do aulos, "mestre da música das flautas", sátiro greco-tropical, sacerdote-mor dos mistérios de Dioniso, desafiante de Apolo, metáfora de Sócrates; saudação pré-trágica, saudade dos confins das terras amazônicas, do povo kamayurá, tupi-guaranis xinguanos, onde "a religião ainda não se perverteu em arte" (Bastos; Bastos, 1995, p. 42) e a palavra ainda não se corrompeu em "lista" grafada (cf. Goody, 1977).

Este ensaio pretende comemorar a maioridade de um tal percurso, selecionando do livro alguns temas para aclarar o caminho, já sob alguns luminares dentre a vasta produção que o mesmo autor deu à luz nestes vinte e um anos entre os marcos das suas duas edições: Bastos (1988, 1990, 1995, 1998, 1999) e o já citado Bastos e Bastos (1995).

Não será portanto aqui descrito o plano da obra que, por se tratar de dissertação de mestrado no original (Bastos, 1978), já o traz em seu prefácio. A esse respeito bastará dizer que ela, a obra do mestrado, é um prospecto estrutural da obra do doutorado (Bastos, 1990). Ambas apresentam larga ambição teórico-metodológica na introdução, sob a forma de uma longa e funda crítica a uma epistemologia ineficaz, objetivando uma gnosiologia ${ }^{1}$ que dê conta da pretensa incompatibilidade entre as musicologias e as humanidades no

\footnotetext{
* Doutorando em Antropologia Social.

1 "uso aqui o termo gnosiologia despido de seu compromisso metafísico, nesse sentido, pois, não se opondo, ele, ao de epistemologia, de matriz mais positivista" (p. 22).
} 
Ocidente. Nos capítulos seguintes, lê-se em ambas as respectivas etnografias acerca da mesma música da mesma gente, e as suas exegeses conjuntas, do povo e do autor, em direção da mencionada crítica. Sob o título de conclusão, as duas obras mostram um post-scriptum ao invés, "antes definições que respostas" (Bastos, 1990, p. 499), situando-as dentro de um "projeto muito mais amplo" (p. 18): no caso do doutorado, a "profecia semiótica" (Bastos, 1990, p. 513) de Saussure (1967) de uma Semântica Musical; do mestrado aqui em questão, da "já profetizada Antropologia da Comunicação" (p. 51) de Hymes (1973).

Aquém da forma similar, o âmago do livro parido há tempos e recém-relançado está na "classificação e nomenclatura de coisas musicais" (p. 18), nas categorias nativas, apresentadas de acordo com os seguintes níveis decrescentes de inclusão:

i) categorias do conhecimento;

ii) categorias de parâmetros acústicos;

iii) categorias de parâmetros musicais;

iv) categorias de intrumentos musicais.

Além de semelhança formal, há agendas comuns às duas obras, em meio às suas introduções, corpos de texto e conclusões, pontos que já chamei de iluminações, postes de luz na carreira do autor. Por se tratar aqui de ensaio maior que resenha, em lugar de examinar o que do livro em resenha é específico, quero clareá-lo na abertura maior da obra. Exemplifico alguns daqueles pontos e em seguida os comento tal como são no livro apresentados e em contraposição ao doutorado vindouro, a princípio na seguinte ordem:

1) a distinção entre o "falar" e o "fazer", homóloga àquela entre "sistema musical" e "metassistema de cobertura verbal" (p. 18), e à posição da Antropologia da Música no seio do corpus scientarum musicarum (p. 19), das humanidades nas musicologias, sendo aquela a versão antropológica dos estudos musicais acadêmicos;

2) o "tema da adaptação ecológica" (p. 20), uma etnografia da percepção;

3) a manipulação dramatúrgico-musical da mito-poética e da história kamayurá; 
4) a visão sistêmica de códigos comunicatórios, aí inclusos mito, música e dança em interação simultânea, configurando a "suíte" cerimonial, "linguagem franca xinguana" (p. 20), constituidora de etnicidade, socialidade e cosmo, e a natureza dos mecanismos intersemióticos no interior dessa suíte, indicação ao invés de tradução. O três "êmico" do cerimonial xinguano, suíte ou "cadeia intersemiótica" conforme nomeado acima, mito-música-dança, se transforma de dado etnográfico, elaboração nativa, em artifício analítico na sua analogia com construtos ternários "éticos", tais como cognição-afecção-psicomotrição, verbo-som-corpo e visual-aural-táctil (Bastos, 1999, p. 7).

Percorrerei esses temas no sentido inverso, dispostos que eles estão em âmbitos teóricos concêntricos, a saber: (4) a música no rito kamayurá; (3) a música e o tempo mítico e ritual; (2) a música como percepto aural principal, sinal de ênfase acústica similar na cognição; (1) a música na etnografia de "audição de mundo" (Bastos, 1999, p. 3). Nessa estranha topologia, o centro dos âmbitos se confunde com os seus perímetros, daí sendo esta ordenação concêntrica mero recurso meu para ordenar o livro no seu contexto bibliográfico, ao mesmo tempo maior e menor que a musicológica dos kamayurá. Se deste livro o objeto específico são as categorias musicais, também se excede ele para além da música, na direção da percepção aural, e a partir daí alcança a dimensão de uma crítica à metafísica platônico-aristotélica.

Porém, alerta leitor! Antes de prosseguir é preciso esclarecer que o autor é antropólogo, contenção inútil se essa opção profissional não condicionasse o seu viés sobre o objeto. Assim, o foco dos círculos de abrangência teórica acima listados se coloca numa geometria humanística, onde a relevância focal se impõe de acordo com o amplitude do universo cultural que descortina: a identidade, a sociedade, o cosmos. É desejo do autor fazer-se sentir à vontade nessa atmosfera acadêmica, e para tal se diveste de unívoca e sectária profissão de fé da música. Escuta-a ele assim como um dentre vários "subsistemas de conhecimento cultural... [um] como outro qualquer" (p. 30, 55). Ainda que (4) coloque-a, ou melhor, veja-a colocada em posição pivotal entre tais subsistemas dentro do sistema ritual; ainda que (3) considere-a como ferramenta de transição entre o contigencial sócio-político e o fundamento sócio-cósmico 
indígena, entre os processos do contato e da história, da hominização e da divinização kamayurá; ainda que (2) valorize o potencial cognitivo da audição face a qualquer percepto visual desta sociedade e cosmo, equacionando o pivô musical do rito com o pivô aural do ser kamayurá, etnônimo exógeno de quem se auto-denomina Apùap, "eu que escuto e toco aerofone" (Bastos, 1999 , p. 4); ainda que (1), enfim, proponha a intradutibilidade da música ${ }^{2}$ em "coisa que se fale" (p. 20). Com todas essas contenções, somos levados a perceber sobretudo o Homem, pelos ouvidos do Índio, ao longo do discurso musical. A música e o ponto de escuta são perspectivas kamayurá, não sendo privilégio gnosiológico do autor. Isto deve ser guardado como acento da obra, desta e das subsequentes.

Vamos às circunferências concêntricas, ponto a ponto, com a numeração devidamente invertida, sem poder conter a necessária tangência entre elas.

1) A natureza da tradução ou falta dela entre sistemas de signos, notadamente entre a música e a língua, que sob esta categoria de "sistema" dividem um "programa comum de investigações" (Bastos 1990, p. 513), é pois o fulcro destes estudos. Fulcro transformante, ao longo destes vinte e um anos: da incongruência à interreferência, a potência designativa e taxonômica das palavras tende a decrescer nos trabalhos do autor. As palavras parecem se impor ao neófito na Antropologia, bem como as notas se impõem ao aprendiz na Música. O que se postula a princípio no livro em foco é, por um lado, o potencial mediador da fala, reprodutor cultural e ferramenta cognitiva primordial, cognitivamente análoga ao código gramatical e sintático da música, a língua como "sistema conversor de todos os outros" (p. 50); por outro lado, a sua incapacidade de congruência semântica em relação à música. É desta forma que o autor faz objeto precípuo do livro das palavras que designam coisas musicais, das mais abstratas e genéricas como o verbo ouvir, às mais concretas e específicas como os nomes dos instrumentos. Era de se esperar que a armação do método, obsessão antropológica, seduzisse-o a tomar caminhos alheios no acesso ao universo musical alienígena. Via de regra o antropólogo é ladrão da ciência do outro, no campo e no gabinete. Assim, é da Psicologia

\footnotetext{
2 “entenda-se, pois, aqui, por tradução aquela forma de conversão onde há possibilidade de perfeita substituição semântica do sistema convertido (linguagem) pelo sistema conversor (metalinguagem)” (p. 55).
} 
que se empresta o esquema pedagógico tripartite da cognição, afetividade e psicomotricidade, tripartição homóloga à "suíte cerimonial" ou "cadeia intersemiótica" por meio da qual se afirmará o caráter pivotal da música, efetuando a transição dos primeiros termos (e.g. o "mito") aos últimos (e.g. a "expressão corporal"), passando pela sua especificidade semântica (i.e. o "sentimento"); assim, se separa o que é falável do que não é: fala-se sim do que é cognoscível - o mito verbalizável - e não se fala de sensação e movimentos - a música e a dança. $\mathrm{O}$ autor insiste que na cognição "a estrutura taxonômica é básica, e a língua falada, típica" (p. 48). Paralelamente, da Linguística se deriva a Etnociência, operador do modelo daquilo que é designável por meio da fala, já identificado conforme supra. A música se coloca no nível do indicável, oposto ao do tradutível no gradiente de congruência à semântica verbal proposta pelo autor; 3 portanto, esta semântica musical é colocada como marginal, objeto mal conhecido no escopo do corpo da tese, já que o objeto específico desta última é, como disse, dentre as "coisas musicais" aquilo que é "coisa" representável, objetificável e rotulável por palavra: categorias do conhecimento, da percepção, de parâmetros musicais dentre os acústicos, de instrumentos. A despeito da eficácia no campo e na academia desta armadura psico-etnocientífica, falha ela em acessar a especificidade musical na sócio-cosmo-ontologia kamayurá, a sua distintividade étnica, a semântica da música que, afinal de contas, lhe confere o status de "condição sine qua non" da identidade indígena e humana deste povo (p. 32), a sua mensagem a todo o universo ao redor. A essas questões se devota o autor em futuros estudos (e.g. 1990, 1998; Bastos; Bastos, 1995), para constatar que afinal indicação é característica de todo e qualquer sistema semiótico, pois o significado da música, da língua e de qualquer código comunicante, está na "ordem diretamente inobservável do conceito", no âmbito do pensamento e da cultura (Bastos, 1990, p. 517). O que equivale, acredito, a tirar a primazia e exclusividade, respectivamente cognitiva e sentimental, das semânticas da palavra e dos sons musicais, para dar-lhes ainda maior especialidade, de maneira a estabelecer a natureza de sua mútua indicação em termos de uma relação de taxonomia ${ }^{4}$ para hierarquia, de ética

3 "assim colocada a de tradução, a relação de indicação se define pela incongruência semântica dos sistemas conversor e convertido, o primeiro apenas, digamos, evocando, indicando o segundo" (p. 55).

4 "o emprego que faço nesta dissertação do conceito de taxonomia é o estritamente etnocientífico, ou seja: padrão classificatório caracterizado pela inclusão vertical e contraste horizontal das categorias" (p. 89). 
(do ethos) para a axionomia (do axios), ${ }^{5}$ do tema para o valor, configurando a ambiência pática e lógica da canção, unitária e unicamente musical. Ora, equacionar os pares verbo : música :: cognoscível : sensível significa associar a cognição à inteligibilidade, excluindo daquela, em troca, a sensibilidade, o que em se tratando de mito- (e musico-) logia seria errôneo (cf. Sousa, 1988a, 1988b), mera versão localizada do mito metafísico que equaciona os pares falar (de música) : fazer (música) :: ver : ouvir :: conhecer : sentir :: inteligir : perceber. Tudo isso são querelas ocidentais, como se dirá adiante, na medida em que nos for lícito deixar escapar o fio-da-meada do nosso ensaio-resenha. Para além dele, do livro que se republica, quero correr o risco de errar ao dizer que o mea culpa parcial que o autor a ele pospõe tende, se pouco o declara, a abdicar da noção de sistema como coisa estanque, e desta forma também abdicar daquela noção de língua como moeda corrente de subsistemas comunicativos, como se só graças a ela fossem eles comensuráveis e igualáveis. Não; se ainda se concede que a fala é o "sistema mediador por excelência de todos os demais" (Bastos, 1990, p. 517), é com a salvaguarda de que as palavras não são apenas construtos concretos ou abstratos, designativos de coisas ou idéias, mas sim moções sonoras em indicação intersistêmica, afecções cognoscíveis por interreferência sinestética, enfim. A imbricação do verbo e do som em torno de um âmbito semântico comum é condição da análise da relação entre língua e música. Conclusão simples, mas tão inovadora: se o objeto referente da música é o metassistema cultural, não basta definir daquele subsistema musical a função de "pivô", sendo necessário perceber-lhe a operação e estrutura, de forma sincrônica e correlata à percepção da musicalização da fala, interpenetração óbvia de sistemas em um complexo sistêmico verbo-musical (Bastos, 1990, 1998; Bastos; Bastos, 1995). Em suma, para se chegar a tal modelo analítico, será necessário deslocar a palavra daquela centralidade semiótica, calcada em seu privilégio cognitivo, e colocá-la no nível de sua articulação sonora, onde a cognição é sensível, para além da intelecção. Em resumo, será preciso tratá-la como música - vale dizer, como mito ritualizado, no sentido eudoriano (Sousa, 1988a, 1988b), para que, enquanto se possa abstrair a sua subdimensão exclusivamente referencial, taxonômica, filológica, se

5 "entendo por axionomia a re-classificação valorativa de urna taxonomia, no caso, de sons que, agora... passam a se estruturar hierarquica, gravitacionalmente" (Bastos, 1990, p. 220). 
vá mais além desta subdimensão, investigando-se a sua afetividade e motricidade, porquanto a palavra é entoada como som musical. Penso que o "modelo linguístico da linguagem" referido pelo autor (p. 50) vem a se mostrar inadequado, tanto analítica quanto semanticamente, não só à música mas à própria língua falada, fato que ele sugere ao cunhar o termo "linguágico" 6 e então assumido no momento posterior em que os termos "tradução" e "indicação" começam a se embolar. ${ }^{7}$ Por ora contudo, na presente obra, a sua intenção é apontar para o ruído na "conversão intersistemas de comunicação" (p. 243), sobretudo cuidando aqui de estruturas verbais, e assim afirmar que música diz algo diverso das palavras de uma gente pouco loquaz (p. 243, 246), ainda que não se diga o quê nem como.

2) Da mesma forma em que, com o tempo, o autor excede modelos epistemológicos (já que a crítica à epistemologia é a sua abertura à questão musical), e desde sempre excede o seu objeto, o estudo do tempo kamayurá passa por um refinamento à medida em que o tema é desenvolvido no seu contexto ritual. Partindo das categorias nativas de mawe e ang, tentativamente glosadas por "mito" e "história", a música é de início lida como a ponte de passagem de um tempo mítico, originário, das coisas arquetípicas, contínuo e eterno, para um tempo histórico, cotidiano, das coisas ostensivamente definidas, discursivo e discreto. Da perspectiva exegética nativa, esta partição é proporcional à tridimensão do ritual, do cosmo ao corpo por meio do som; da perspectiva analítica do estudante, ela está para a oposição de sincronia a diacronia, ou no seu próprio dizer, de paradigma a sintagma (p. 109, 110). Porém alí no livro a passagem é envisada no sentido inverso, da réplica ao modelo, do caos à ordem (p. 203), uma construção aliás muito ao gosto do etnógrafo: a concepção do ritual para reordenar, paralela à auto-concepção da sua própria tarefa etnográfica (cf. a crítica à moderna etnografia da ordenação cultural do caos natural em Taussig, 1987, p. 390, 441-443), enquanto o kamayurá diz ao pé da letra que o faz simplesmente para "ficar alegre" (p. 141); gosto de

\footnotetext{
6 “'linguágico' é neologismo meu, adjetivo de 'linguagem', não só o de 'língua falada' (que seria 'linguístico')" (p. 192).

7 “sim - e isto eu não percebera [n'A Musicológica Kamayurá] - porque a língua, pobre dela!, só conta consigo própria para se tentar traduzir e a tradução é um exercício antes da diferença que da identidade" (Bastos, 1990, p. 517). "a referida 'tradução' não deve ser pensada em termos sinonímicos ou da reprodução dos mesmos significados pelos diferentes subsistemas significantes" (Bastos, 1998, p. 18).
}

Horizontes Antropológicos, Porto Alegre, ano 5, n. 11, p. 185-199, out. 1999 
índio. Também ao gosto do autor é a visão do mito ritualizado como reificação da poíesis aristotélica, imitação da história potencial de acordo com a necessidade e verossimilhança (cf. a Poetica de Aristóteles, apud Sousa, 1966). Mantendo-se fiel à noção de função eco-axiológica da música (Bastos, 1995, p. 2), o seu caráter de ciência dos sentimentos (Bastos, 1995, p. 4, 1998, p. 16), bem como a função mito-reificadora da sua dramatização, seguimos em seus trabalhos posteriores para mais que a sua função ritual como perseguição de modelo, ordem ou forma ideal. Esta ultrapassagem se dá através de estudos mais exaustivos do cerimonial e da música correspondente, nomeadamente do Yawari (Bastos, 1990), este sendo brevemente comparado ao Kwarùp (Bastos, 1998). Aqui temos mais uma vez a superação da visão sistêmica da cultura e das coisas antropológicas em geral, em prol do processual e agenciai. Afinal, rito não apenas representa mas apresenta (Bastos; Bastos, 1995, p. 5; Bastos, 1998, p. 17); não é só originário mas de fato origina o contrato entre humanos e divinos (Bastos, 1990, 1995, 1998). Mais que imitação de um modelo, ordem ou programa, a música, sinesteticamente pensada, é "imitação infinita da própria imitação" (1998, p. 18). Não só as fronteiras do "sistema musical", enquanto sistema, são permeabilizadas conforme acima, mas a própria categoria heurística de "música" o é. Sugestões verbais, musicais e coreográficas apontam para sentidos não-exclusivos, apreensíveis só por mútua referência, mensagens de sinestesia nativa (Bastos, 1998, p. 17). Note-se que se as fronteiras dos "sistemas" se fazem tênues, os "códigos" se fazem mais nítidos, no sentido da sua especificidade estrutural. A estrutura global verbo-musical, o autor sugere então, aponta para a temporalidade dos mitos e dos ritos, os pensamentos "progressivo", "progressivo-regressivo" e "regressivo" (Bastos, 1998, p. 13, 18). Não se limita essa estrutura, mais uma vez porém, àquela redução da cognição à classificação taxonômica, "inclusão vertical e contraste horizontal de categorias" (p. 89, apud Tyler, 1969; Spradley, 1972), ainda que tal redução se enquadre nas múltiplas relações fono-tonais, gramatico-agógicas elicitadas por sua projeção em papel. Mesmo que não exclusivamente, a música, após o mestrado, ainda é objeto de engenharia: diagramas, tabelas, códigos e outras manhas em Bastos 1990...

3) Um dos mais recentes textos do autor (1999) volta à sua nota inaugural acerca da percepção e da cognição dos kamayurá, presente no livro aqui em foco (p. 101-125). Levando-se em conta que aquele texto não faz mais que 
reportar a etnografia a debates recentes na Antropologia, percebe-se onde está uma das suas mais amplas e originais contribuições, ainda que seja breve. Ao investigar o léxico designativo do acústico na língua dos índios, surpreendemos no perceber e inteligir sons, bem como no produzir sons perceptíveis e inteligíveis, o universo do som envolvente ao planeta do conhecimento kamayurá, e a fono-audição como o próprio diacrítico kamayurá de humanidade (p. 62, 103, 141, 154). Esta constatação é fruto da hipótese de que a ênfase acústica, no sentido inverso, é "reelaboração metafórica no plano conceptual", i.e. cognitivo, do percepto dominante, neste caso os sons (p. 102). Esta ambiência adaptativo-cultural "sônica" equivale a uma "visão de mundo fono-aural", que o leitor me perdoe a força de expressão contraditória porém mais abrangente que o "world hearing” entitulando Bastos 1999. É a partir daí que o autor nos traz para junto desses índios a caminho de um embate gnosiológico com a "paixão eidética, i.e. visual, do Ocidente" (p. 85), o "só acredito vendo" ou o "só sente o coração o que os olhos vêem". ${ }^{8}$ Alguns dos avatares ocidentais, a Bíblia, Aristóteles e Platão, são os oponentes invocados, as proposições do nexo pático entre a palavra e a visão, a episteme de encontro a qual vem a gnosis auditiva e musical amazônica. Aí neste encontro transcultural reside o escopo maior do livro, seu ponto de partida e de chegada, núcleo e periferia, assim como o contracanto do percurso que aqui celebramos, pontuado pelas referências citadas. Entretanto, é aí na passagem à sua amplitude mais vasta que se encontra também a maior dificuldade que nele encontrei, a saber: a articulação entre as oposições branco: índio:: visão: audição de um lado; do outro a tão discutida relação verbo: música. Temos de um lado, o de lá, um sofisticado universo sonoro como dado de realidade de um conhecimento que privilegia o campo fono-aural, o que acaba por legitimá-lo como objeto de estudos; cá do nosso lado, temos um privilégio à visão como canal do conhecimento. Essa inversão em escala de inteligibilidade é fator negativo de comensurabilidade intercultural. Tudo muito bem; tudo isso é estratégia e justificativa forte para pesquisa antropológica. Contudo transferir esta relação intercultural para a questão da mudez do sentir, uma das "querelas que... acompanham o fazer humanístico do Ocidente desde mesmo os primórdios" (p. 41), ou seja, tentar equacionar o "ver" com o "falar" em oposição ao "escutar" e, digamos,

8 "even the word 'idea' seems to come from a root which means 'to see"” (Bastos, 1999, p. 7), "idéia" categoricamente reforçada por classicistas do calibre de Hare (1996).

Horizontes Antropológicos, Porto Alegre, ano 5, n. 11, p. 185-199, out. 1999 
o "cantar", ou ainda, opor o "viso-verbal" ao "auro-musical”, é, aos meus olhos e ouvidos, uma complicação desnecessária ao quadro. Verbo vs. música, dilema antropológico e antinomia ocidental, remete a um outro conjunto de dicotomias homólogas apresentado logo mais abaixo, problemas paroquiais nossos. Mais do que rascunhar tais equações, que por negação colocam em evidência as nossas paixões e fraquezas, brilhante no autor é ter perseguido a solução às nossas questões teórico-metodológicas tomando partido das transformações sensoriais e cognitivas entre os dois universos. Em suma matemática, em vez de equacionar o "dois" intracultural ao "dois" de contraste intercultural, i.e. palavra: som:: visão: audição, interessa a nós equacionar o nosso "dois" dilemático primeiro ao "três" kamayurá dantes referido, já que este, além de manipulável em análise, se desdobra em outras dualidades também, que também são intraculturais embora não dilemáticas, conforme acima: mito-história, perene-transitório, circular-linear, paradigma-sintagma. $2: 2=$ $2: 2$ é tautologia que não ultrapassa barreiras culturais, é mera constatação. 2 : $3=3: 2$ é analogia ilógica, desconsiderável caso o seu termo central, vértice do triângulo cerimonial, a música e a fono-audição, não apontasse para o "um" almejado desde há muito antes da metafísica por poetas pré-socráticos, quando logos era bem mais que a "-logia" da analogia e tautologia, mais do que hoje se quer compreender por lógica (cf. Heidegger, 1998, p. 195-405). O "um" enfim alcançado (em Bastos, 1990) é o som: verbo e música acerca do mesmo, a junção entre o mito, meta-narrativa e explicação, e a dança, sua encenação, criando o ambiente onde se dá a expressão sociocósmica, apresentando o recorrente tempo sempiterno na diacronia cotidiana. $\mathrm{O}$ "três" é a ponte entre eles e nós, e o "um” é o seu meio e síntese.

4) O arcabouço instrumental, teoria e método, é resposta ao dilema que, apostamos, foi tanto dado de realidade na tradição da área onde aportou o autor quanto objeto de sofridas decisões na carreira de quem se propôs a pesquisar música; coisa que para muitos, por ser pesquisa "falada", exclui o "fazer" música, já que, como o livro mesmo já o diz, ambas as coisas "delimitam formas de conhecimento muito diferentes" (p. 18). Essa dicotomia é homóloga àquelas entre o verbal e o musical, a expressão e o conteúdo (termos favorecidos pelo autor, apud Lyons, 1974), o meio e a mensagem e, em última instância, o conceito e o percepto, a intelecção e a afecção. O autor aqui mantém que as analogias entre tais dicotomias são válidas sem que os termos análogos 
necessariamente se equivalham, quer dizer, a palavra não é o "conceito" inteligível (ou idéia visível) de qualquer "nota" percebida; os respectivos sentidos, verbal e musical, só seriam elicitáveis "via o meio próprio" (p. 20), graças à incongruência semântica entre verbo e música. Ora, vimos que tais bipartições antinômicas só fazem sentido se pensarmos a língua e a cultura na sua matriz intelectiva, etnocientífica, que por sua vez é projeção de matriz há muito designada pelos primeiros metafísicos gregos. Como as obras sucedâneas do autor do livro em análise bem nos mostram, tais antinomias não levam em conta o caráter não-designativo ou interreferencial de qualquer linguagem, nem tampouco a transformação músico-poética da língua, tão conspícua dentro de uma canção, se quisermos crer, como os kamayurá, que a palavra vai "dentro" do som. Quero crer eu que essas nossas homologias, dilemas intraculturais, visam tão-somente um vocabulário comum com a metafísica platônico-aristotélica, com vistas à subversão da sua tautologia intelectual (cf. o De Anima HI 4-5 de Aristóteles, apud Zingano, 1998) onde se aprisiona o corpus scientiarum musicarum. A tradição que identifica o "dizer" musical, significado, com o seu "fazer", significante, opondo todos os dois ao "falar" a respeito de música, esta tradição precisará ser subvertida para que se as resgate, música e Musas, do reino do incognoscível, da afasia sensível, da tautologia perceptual. O fio de Ariadne deste labirinto metafísico, conforme é apresentado na presente obra, parece sair do seu capítulo quarto, Sociomusicologias Kamayurá, rumo à saída via a "estrutura do discurso cerimonial" e, consequente e concomitantemente, à estrutura musico-coreográfica. $\mathrm{O}$ que mais poderia ser um dizer próprio, apropriado "pela" música, não preposicionando a fala "sobre" o som, e sim ao contrário colocando-a "dentro" dele, conectando este ao sentido, tanto o verbal quanto o musical, desta forma assim sob um plano singular?

A Antropologia de Rafael Bastos é, no mínimo, peculiar e idiossincrática, sem contradição à sua erudição e domínio da bibliografia indisputáveis. No máximo, ela é originária e original, trazendo à luz os mais fecundos luminares nos estudos musicais da Amazônia, estudos estes que, se nada mais se pudesse provar, Rafael provou de forma pioneira serem de essencial pertinência. É ela peculiar e original porque se confunde com uma Musicologia toda sua, rompendo barreiras disciplinares. É originária e idiossincrática porque tudo o que Rafael diz parece aparecer como uma notinha de pé-de-página aos gregos: ao "tudo flui" ou ao "sem pre o mesmo acerca do mesmo"... (Bastos, 1998, p. 18). Se se ignorasse a peculiaridade e idiossincrasia, a originalidade 
e originariedade desta sua Antropologia, n’A Musicológica Kamayurá Rafael pareceria, não obstante os brados de revolta, identificar-se com burguês que aliena aquilo que é do homem daquilo que o homem faz, incapacitando-o nesse caso de "falar" sobre o "dizer" da música. Quem o conhece só por esta obra temeria por afirmações tais como "quando se fala de Etnomusicologia está se discursando sobre a Antropologia" (p. 41), ou "o caminho da Etnomusicologia até a Antropologia da Comunicação... quer significar... tentativa de superação crítica sua" (p. 241-242), afirmações estas que, de constatações, poderiam ser tomadas pelo leitor mais desatento como declarações de fé profissional. Felizmente isso tudo só vem a ser atestado de óbito que ele vem a decretar às ciências "etno-", paradoxalmente não só a Etnomusicologia mas a própria Etnociência, no fundo todas elas tão-simplesmente etno-cêntricas. Está claro, como foi dito acima, que Rafael é antropólogo, e como tal afirma com razão a primazia epistemológica da Antropologia sobre a Musicologia no âmbito das humanidades ocidentais; porém Rafael também é músico, exímio violonista e compositor, e se o seu objeto é sempre e desde o início uma gnosiologia, teoria e método transdisciplinar e meta-metafísico, o que busca é tão-somente o logos e o pathos da música, enquanto coisa quintessencial do homem, para além de um fazer artesanal, artístico e ocidental. Para além do patriarca disciplinar Merriam (1960), que transitou da noção da "música na cultura" para a da música "como" cultura, buscamos a música que "é" a cultura, a saber, o homem. Ontologia. Pelo menos é isso que eu gostaria de ir buscar e ouvir do Rafael.

Por fim, as próprias juras do autor de obediência às exegeses nativas soam de menor relevância que a clara sensação de que a sua teoria e o método finais são ditadas a posteriori pelo seu objeto, a saber: a oposição (simbólica e) complementar entre verbo e música. Som e sentido passam a ser um substrato comum, o real transcultural da Antropologia desta música, altamente desconfiada das palavras, ainda que movida pelo ouvido. Ao análogo "modelo dualista" tradicional de música vs. cultura (p. 63), o autor opõe a posição razoável, tanto de brancos quanto de índios, a aritmética "nota + palavra = música". Em outras palavras - aquelas com as quais nos acenam os kamayurá - a dimensão verbo-musical privilegiada passa a ser não a taxonomia, qual uma grade cultural sobre um continuum natural moderno, um really made-up sobre um really real, a estrutura cognitiva formal, ideal, universal, intangível, posto que pertinente ao intelecto mas não ao percepto; mas sim, claro, o privilégio é concedido à lógica pática, um intelecto que se amarra a um percepto, oposto e 
complementar à tautologia aristotélica e à alegoria platônica (cf. a Republica de Platão, apud Cornford, 1955), que por sua vez se amarram à intelecção enquanto cortam as amarras da percepção. A Musicologia deste homem é, assim, uma musico-patia ou uma pato-logia. Voltando ao jogo numérico com o "três êmico" e o "ternário ético", as cerimônias, suítes ou cadeias: nem é o mito mera cognição verbal, nem a música só emoção, nem bem a dança apenas movimento corporal. Tal embaralhamento disciplinar e analítico é anunciado com todas as letras na introdução à tese de doutorado que a obra sob a minha lente projeta (introdução aquela publicada como Bastos, 1995). A projetada dimensão verbo-visual, auro-musical, unidade dual do mito-música da tridimensão do rito-cerimônia é tal qual o triângulo humano-divino-mítico eudoriano (cf. Sousa, 1988a, p. 7-43): é tanto alegoria - todos os sentidos, domínios semânticos se acenando - quanto tautegoria - sem deixar de falar de outrem, se pronuncia.

\section{Referências}

BASTOS, R. J. de M. A musicológica kamayurá: para uma antropologia da comunicação no Alto Xingu. Brasília: Fundação Nacional do Índio, 1978.

BASTOS, R. J. de M. Música, cultura e sociedade no Alto-Xingu: a teoria musical dos índios kamayurá. Folklore Americano, Ciudad de México: IPGH, n. 45, p. 49-71, enero-junio 1988.

BASTOS, R. J. de M. A Festa da Jaguatirica: uma partitura críticointerpretativa. Tese (Doutorado)-Universidade de São Paulo, São Paulo, 1990.

BASTOS, R. J. de M. Esboço de uma antropologia da música: para além de uma antropologia sem música e de uma musicologia sem homem. Anuário Antropológico, Rio de Janeiro: Tempo Brasileiro, n. 93, p. 9-73, 1995.

BASTOS, R. J. de M. Ritual, história e política no Alto-Xingu: observação a partir dos kamayurá e da festa da jaguatirica (Yawari). Antropologia em Primeira Mão, Ilha de Santa Catarina: PPGAS/UFSC, n. 27, 1998.

BASTOS, R. J. de M. A musicológica kamayurá: para uma antropologia da comunicação no Alto Xingu. 2. ed. Florianópolis: Editora da UFSC, 1999. 
BASTOS, R. J. de M. Apùap world hearing: a note on the Kamayurá phonoauditory system and on the anthropological concept of culture. Antropologia em Primeira Mão, Ilha de Santa Catarina: PPGAS/UFSC, n. 32, 1999.

BASTOS, R. J. de M.; BASTOS, H. J. de M. A Festa da Jaguatirica, primeiro e sétimo cantos: introdução, transcrições, traduções e comentários. Antropologia em Primeira Mão, Ilha de Santa Catarina: PPGAS/UFSC, n. 2, 1995.

CORNFORD, F. M. (Ed.). The Republic of Plato V. Oxford: Clarendon Press, 1955.

GOODY, J. The domestication of the savage mind. Cambridge: Cambridge University Press, 1977.

HARE, R. M. Plato. Oxford: Oxford University Press, 1996.

HEIDEGGER, M. Heráclito. Rio de Janeiro: Relume Dumará, 1998.

HYMES, D. A antropologia da comunicação. In: DANCE, F. E. X. Teoria da comunicação humana. São Paulo: Cultrix, 1973. p. 9-56.

LYONS, J. Introduction to theoretical linguistics. Cambridge: Cambridge University Press, 1974.

MERRIAM, A. Ethnomusicology, discussion and definition of the field. Ethomusicology, n. 4, p. 107-114, 1960.

SAUSSURE, F. de. Curso de linguística geral. Buenos Aires: Losada, 1967.

SOUSA, E. de. (Ed.). Poética de Aristóteles. Porto Alegre: Globo, 1966.

SOUSA, E. de. Mitologia I: mistério e surgimento do mundo. Brasília: Editora UnB, 1988a.

SOUSA, E. de. Mitologia II: história e mito. Brasília: Editora UnB, 1988b.

SPRADLEY, J. P. (Ed.). Culture and cognition. San Francisco: Chandler, 1972. 
TAUSSIG, M. Shamanism, colonialism, and the wild man: a study on terror and healing. Chicago: The University of Chicago Press, 1987.

TYLER, S. A. (Ed.). Cognitive anthropology. New York: Holt, 1969.

ZINGANO, M. Razão e sensação em Aristóteles: um ensaio sobre De Anima III 4-5. Porto Alegre: L\&PM, 1998. 